\title{
Determination of fluorotelomer alcohols and their degradation products in biosolids-amended soils and plants using ultra-high performance liquid chromatography tandem mass spectrometry
}

\author{
Hongna Zhang ${ }^{\mathrm{a}}$, Bei Wen ${ }^{\mathrm{a}, *}$, Xiaoyu $\mathrm{Hu}^{\mathrm{b}}$, Yali Wu ${ }^{\mathrm{a}}$, Lei Luo ${ }^{\mathrm{a}}$, Zien Chen ${ }^{\mathrm{a}}$, \\ Shuzhen Zhang ${ }^{\mathrm{a}}$ \\ a State Key Laboratory of Environmental Chemistry and Ecotoxicology, Research Center for Eco-Environmental Sciences, Chinese Academy of Sciences, \\ Beijing 100085, China \\ ${ }^{\mathrm{b}}$ Beijing Center for Disease Prevention and Control, Beijing 100031, China
}

\section{A R T I C L E I N F O}

\section{Article history:}

Received 20 March 2015

Received in revised form 27 May 2015

Accepted 27 May 2015

Available online 4 June 2015

\section{Keywords:}

FTOHs

Degradation products

Biosolids-amended soil

Plant

UPLC-MS/MS

\begin{abstract}
A B S T R A C T
Degradation of fluorotelomer alcohols (FTOHs) was recognized as an additional source of perfluorocarboxylic acids (PFCAs). Quantification of FTOHs and their degradation products can help shed light on the sources and fates of PFCAs in the environment. In this study, an analytical method was developed for the determination of 6:2 and 8:2 FTOHs, and their degradation products of poly- and perfluorinated acids, including fluorotelomer saturated and unsaturated carboxylic acids (FTCAs and FTUCAs), secondary polyfluorinated alcohols and PFCAs in biosolids-amended soils and plants using ultra-high performance liquid chromatography tandem mass spectrometry (UPLC-MS/MS). The extract efficiencies of different methods including ethyl acetate and methanol (MeOH) for FTOHs and acetonitrile, $\mathrm{MeOH}$, methyl tertbutyl ether (MTBE), NaOH-MeOH and $\mathrm{NaOH}-\mathrm{MTBE}$ for poly- and perfluorinated acids were tested. The results showed that $6: 2$ and $8: 2$ FTOHs and their degradation products could be simultaneously and satisfactorily extracted by $\mathrm{MeOH}$, cleaned up by Envi-Carb graphitized carbon and solid phase extraction, respectively, and determined by UPLC-MS/MS separately. $\mathrm{NaOH}$ in the extractant caused the conversion of 6:2 FTCA and 8:2 FTCA into the corresponding FTUCAs. The selected methods have matrix recoveries ranged from $52 \%$ to $102 \%$, and detection limits of $0.01-0.46 \mathrm{ng} / \mathrm{g}$ dry weight for FTOHs and their degradation products in soil and plant. The optimized method was applied successfully to quantify FTOHs and their degradation products in two biosolids-amended soils and plants. The total concentrations of FTOHs in the soils were $44.1 \pm 5.8$ and $82.6 \pm 7.1 \mathrm{ng} / \mathrm{g}$, and in plants tissues $3.58 \pm 0.25$ and $8.33 \pm 0.66 \mathrm{ng} / \mathrm{g}$. The total concentrations of poly- and perfluorinated acids in the soils were $168.0 \pm 13.2$ and $349.6 \pm 11.2 \mathrm{ng} / \mathrm{g}$, and in plants tissues $78.0 \pm 6.4$ and $75.5 \pm 5.3 \mathrm{ng} / \mathrm{g}$.
\end{abstract}

(C) 2015 Elsevier B.V. All rights reserved.

\section{Introduction}

Perfluoroalkyl acids (PFAAs), including perfluorocarboxylic acids (PFCAs) and perfluorosulfonic acids (PFSAs), have been manufactured and used for more than 60 years. They are employed in materials such as surfactants, lubricants, varnishes, pesticides and fire retardant foams, the subsequent disposal of which results in the wide detection of these compounds in various environmental media [1-4] and biological species [5-7]. Because of their ubiquitous occurrence, environmental persistence [8], bioaccumulation

\footnotetext{
* Corresponding author. Tel.: +86 10 62849329; fax: +86 1062923563.

E-mail address: bwen@rcees.ac.cn (B. Wen).
}

[9] and potential toxicity [10], PFAAs have raised serious concerns. PFAAs may enter the environment through direct manufacturing emissions, releasing from products during their use and disposal, as well as through indirect precursor transformation [11]. With effective reduction in release from direct sources in recent years, exploring the indirect sources of PFAAs has become increasingly important [11-13].

As raw materials used to produce fluoropolymers and fluorosurfactants, fluorotelomer alcohols (FTOHs) are applied in a variety of industry and households [14]. Degradation of FTOHs has been recognized as an additional source of PFCAs in the environment [11]. Substantial information is available on abiotic [15-17] and biotic [18-23] degradation of FTOHs under laboratory conditions. Ellis et al. [15] reported FTOHs could be degraded in the 
atmosphere to yield a homologous series of PFCAs through peroxy radical cross reactions. Brandsma et al. [23] found that fluorotelomer saturated carboxylic acids (FTCAs) and fluorotelomer unsaturated carboxylic acids (FTUCAs) were the major products detected in rainbow trout following dietary exposure to FTOHs. Biodegradation of 8:2 FTOH in aerobic soils shared common pathways as those reported in aerobic activated sludge, mixed bacterial culture and mammalian metabolism, which proceeded via saturated and unsaturated fluorotelomer carboxylic acid intermediates [18]. In these studies, different degradation intermediates of FTOHs, such as poly- and perfluorinated acids, fluorotelomer aldehydes and secondary polyfluorinated alcohols, and terminal degradation products of PFCAs were identified, which helped unveil the degradation pathway of FTOHs, and further deduced the source of PFCAs in the environment.

Sewage sludge generated in wastewater treatment plants (WWTPs) is widely considered as an important sink of PFAAs and their precursors [24-26]. Land application of treated sewage sludge (biosolids) may release PFAAs and their precursors into the soils [27-29]. Yoo et al. [27] and Washington et al. [29] reported the accumulation of PFAAs and FTOHs in soils as a result of land use of biosolids from industrial sources. These compounds in the contaminated soils may enter into the food chain by plant uptake and exert a potential health risk. Yoo et al. [7] optimized extraction methods to quantify PFAAs and FTOHs in plants from biosolids-amended fields using liquid chromatography/tandem mass spectrometry (LC/MS/MS) and gas chromatography/mass spectrometry (GC/MS), respectively. Wen et al. [30] determined the accumulation of PFAAs in wheat (Triticum aestivum L.) grown in biosolids-amended soils. However, information about the degradation of FTOHs in biosolidsamended soils and plants under field condition is limited.

To evaluate the risks of PFAAs following biosolids land application, the degradability of precursors should be taken into account. Thus, it is essential to establish fast and reliable analytical methods for precursors and their intermediates and terminal metabolites in biosolids-amended soils and plants. While there are a number of peer-reviewed publications reporting extraction methods for PFAAs and FTOHs in solid and biological matrices [28,31-34], methodological studies on the extraction of FTOHs and their degradation products from plants are limited. In this study, the efficiency of different extractants, which have been reported for extracting PFAAs and FTOHs from solid and biological samples [7,26,30,35-37], including acetonitrile (ACN), methanol (MeOH), methyl tert-butyl ether (MTBE), NaOH-MeOH and NaOH-MTBE for the extraction of FTOHs degradation products of poly- and perfluorinated acids, and ethyl acetate (EtOAc) and $\mathrm{MeOH}$ for the extraction of FTOHs, was tested. The results showed that both FTOHs and their degradation products of poly-perfluorinated acids could be extracted by $\mathrm{MeOH}$ efficiently. The extracts were then subjected to cleanup prior to determination using ultra-high performance liquid chromatography tandem mass spectrometry (UPLC-MS/MS). The optimized method was then applied to the determination of two widely used FTOHs, 6:2 and 8:2 FTOHs [20], and their degradation products in biosolids-amended field soil and plant samples. To the best of our knowledge, this is the first report to extract FTOHs and their degradation products simultaneously in soils and plants sampled from biosolids-amended field and determine the analytes using UPLC-MS/MS.

\section{Materials and methods}

\subsection{Reagents and standards}

Three FTOHs and 13 poly- and perfluorinated acids, including six PFCAs, five FTCAs and two FTUCAs were examined in this study (Table 1). Purities of all the analytical standards were $\geq 97 \%$. 6:2 FTOH and 8:2 FTOH were purchased from Matrix Scientific (Columbia, SC, USA). PFBA, PFPeA, PFHxA and PFHpA were from J\&K Scientific Ltd. (Beijing, China). PFOA was from Strem Chemicals Inc. (Newburyport, MA, USA). PFNA was from Alfa Aesar (Ward Hill, MA, USA). 4:3 FTCA and 7:3 FTCA were from Apollo Scientific Ltd. (Bredbury, UK). 5:3 FTCA, 6:2 FTUCA, 6:2 FTCA, 8:2 FTUCA, 8:2 FTCA, 7:2 sFTOH and stable isotope-labeled standards M6:2 FTOH, M8:2 FTOH, MPFBA, MPFHxA, MPFOA, MPFNA, M6:2 FTUCA, M6:2 FTCA, M8:2 FTUCA, M8:2 FTCA were from Wellington Laboratories Inc. (Guelph, Ontario, Canada).

All reagents were of analytical reagent grade or better. Tetrabutyl ammonium hydrogen sulfate (TBAHS), sodium carbonate $\left(\mathrm{Na}_{2} \mathrm{CO}_{3}\right)$, sodium hydroxide $(\mathrm{NaOH})$, ethanolamine and acetic acid $\left(\mathrm{CH}_{3} \mathrm{COOH}\right)$ were purchased from Sigma-Aldrich Chemical (Milwaukee, WI, USA). Weak anion exchange (Oasis ${ }^{\circledR}$ WAX, $6 \mathrm{~cm}^{3}$, $150 \mathrm{mg}, 30 \mu \mathrm{m}$ ) solid phase extraction (WAX-SPE) cartridges were purchased from Waters Corp. (Milford, MA, USA). Supelclean graphitized carbon (ENVI-Carb) was obtained from Supelco Inc. (Bellefonte, PA, USA). ACN, MeOH and MTBE (Fisher Chemical, Firlawn, NJ, USA) were of HPLC grade. Purified water obtained by a Milli-Q Synthesis water purification system (Millipore, Bedford, MA, USA) was used throughout the experiment.

Reference standards solutions of three FTOHs, 13 poly- and perfluorinated acids, and isotope labeled internal standards were made in $\mathrm{MeOH}$, stored in sealed glass containers, and put into $-20^{\circ} \mathrm{C}$ refrigerators.

\subsection{Soil and plant samples}

Explorative evaluations were performed using uncontaminated soils and maize plants (blanks) collected from an experimental field at Beijing Academy of Agriculture and Forestry Sciences. After the optimization process was completed, the established method was used to determine FTOHs and poly- and perfluorinated acids concentrations in biosolids-amended soils and plants. Two soil samples and two maize plant samples were collected from biosolids-amended agricultural fields in Dezhou, Shandong province, China ( $37^{\circ} 20^{\prime} \mathrm{N}, 116^{\circ} 38^{\prime} \mathrm{E}$ ) in September 2013. Soil samples were taken from the cultivated surface layer $(0-20 \mathrm{~cm})$, freeze-dried, ground, and screened through a MeOH-washed, $2 \mathrm{~mm}$ stainless-steel sieve to remove large particles. The selected soil properties are given in Table S1 in the Supplementary materials.

Plant samples were divided into roots, stems and leaves. The subsamples of maize were washed thoroughly with tap water and Milli-Q water sequentially, freeze-dried and ground. All dried samples were stored at $-20^{\circ} \mathrm{C}$ before analysis.

\subsection{Selection of extractants for FTOHs and Envi-Carb graphitized carbon cleanup}

To evaluate the extraction efficiency of EtOAc and $\mathrm{MeOH}$, recovery tests for 6:2 FTOH, 7:2 sFTOH and 8:2 FTOH in soils and plant roots and shoots were conducted. Two grams of blank soils or $0.5 \mathrm{~g}$ blank plant tissues were weighed in $15 \mathrm{~mL}$ polypropylene (PP) centrifuge tubes. Before extraction, $50 \mu \mathrm{L}$ of $6: 2 \mathrm{FTOH}, 7: 2 \mathrm{sFTOH}$ and $8: 2 \mathrm{FTOH}$ mixture solutions ( $200 \mathrm{ng} / \mathrm{mL}$ for each analyte in $\mathrm{MeOH}$ ) were added and aged for $24 \mathrm{~h}$.

All samples were extracted by EtOAc according to the method of Yoo et al. [7] with some modifications. Briefly, $5 \mathrm{~mL}$ of water and $5 \mathrm{~mL}$ of EtOAc were added to the samples sequentially and mixed. The samples were then kept in a constant-temperature shaker (ZWY-210, Shanghai Zhicheng Analytical Instrument Manufacturing Co., Ltd., Shanghai, China) at $25^{\circ} \mathrm{C}$ for extraction. After $8 \mathrm{~h}$, the samples were centrifuged $(2686 \times \mathrm{g}, 20 \mathrm{~min})$ to consolidate the EtOAc fraction. This extraction step was repeated twice. All organic 
Table 1

List of target compounds analyzed, and the MS/MS parameters used.

\begin{tabular}{|c|c|c|c|c|c|c|}
\hline Acronym & Chemical name & CAS registry number & Formula & $\begin{array}{l}\text { Quantitation } \\
\text { transition }(m / z)\end{array}$ & Cone voltage $(\mathrm{V})$ & $\begin{array}{l}\text { Collision } \\
\text { energy }(\mathrm{eV})\end{array}$ \\
\hline $6: 2 \mathrm{FTOH}$ & 6:2 fluorotelomer alcohol & $647-42-7$ & $\mathrm{~F}\left(\mathrm{CF}_{2}\right)_{6} \mathrm{CH}_{2} \mathrm{CH}_{2} \mathrm{OH}$ & $362.97>255.04$ & 12 & 28 \\
\hline 7:2 sFTOH & $\begin{array}{l}\text { 7:2 secondary } \\
\text { polyfluorinated alcohol }\end{array}$ & 24015-83-6 & $\mathrm{F}\left(\mathrm{CF}_{2}\right)_{7} \mathrm{CHOHCH}_{3}$ & $393.00>219.00$ & 20 & 15 \\
\hline $8: 2 \mathrm{FTOH}$ & $8: 2$ fluorotelomer alcohol & $678-39-7$ & $\mathrm{~F}\left(\mathrm{CF}_{2}\right)_{8} \mathrm{CH}_{2} \mathrm{CH}_{2} \mathrm{OH}$ & $462.97>355.00$ & 14 & 18 \\
\hline PFBA & Perfluorobutyric acid & $375-22-4$ & $\mathrm{~F}\left(\mathrm{CF}_{2}\right)_{3} \mathrm{COOH}$ & $212.97>169.03$ & 16 & 8 \\
\hline PFPeA & Perfluoropentanoic acid & $2706-90-3$ & $\mathrm{~F}\left(\mathrm{CF}_{2}\right)_{4} \mathrm{COOH}$ & $262.97>219.03$ & 14 & 6 \\
\hline PFHxA & Perfluorohexanoic acid & $307-24-4$ & $\mathrm{~F}\left(\mathrm{CF}_{2}\right)_{5} \mathrm{COOH}$ & $312.97>269.03$ & 12 & 12 \\
\hline PFHpA & Perfluoroheptanoic acid & $375-85-9$ & $\mathrm{~F}\left(\mathrm{CF}_{2}\right)_{6} \mathrm{COOH}$ & $362.97>319.04$ & 14 & 12 \\
\hline PFOA & Perfluorooctanoic acid & $335-67-1$ & $\mathrm{~F}\left(\mathrm{CF}_{2}\right)_{7} \mathrm{COOH}$ & $412.97>368.97$ & 16 & 8 \\
\hline PFNA & Perfluorononanoic acid & $375-95-1$ & $\mathrm{~F}\left(\mathrm{CF}_{2}\right)_{8} \mathrm{COOH}$ & $462.97>419.04$ & 14 & 8 \\
\hline $4: 3$ FTCA & $4: 3$ polyfluorinated acid & $80705-13-1$ & $\mathrm{~F}\left(\mathrm{CF}_{2}\right)_{4} \mathrm{CH}_{2} \mathrm{CH}_{2} \mathrm{COOH}$ & $291.03>187.03$ & 18 & 12 \\
\hline 5:3 FTCA & $5: 3$ polyfluorinated acid & $914637-49-3$ & $\mathrm{~F}\left(\mathrm{CF}_{2}\right)_{5} \mathrm{CH}_{2} \mathrm{CH}_{2} \mathrm{COOH}$ & $340.97>237.03$ & 18 & 12 \\
\hline 7:3 FTCA & 7:3 polyfluorinated acid & $812-70-4$ & $\mathrm{~F}\left(\mathrm{CF}_{2}\right)_{7} \mathrm{CH}_{2} \mathrm{CH}_{2} \mathrm{COOH}$ & $441.03>337.04$ & 22 & 14 \\
\hline 6:2 FTUCA & $\begin{array}{l}\text { 6:2 fluorotelomer } \\
\text { unsaturated carboxylic } \\
\text { acid }\end{array}$ & $70887-88-6$ & $\mathrm{~F}\left(\mathrm{CF}_{2}\right)_{5} \mathrm{CF}=\mathrm{CHCOOH}$ & $356.97>293.01$ & 14 & 16 \\
\hline $6: 2$ FTCA & $\begin{array}{l}\text { 6:2 fluorotelomer } \\
\text { saturated carboxylic acid }\end{array}$ & $53826-12-3$ & $\mathrm{~F}\left(\mathrm{CF}_{2}\right)_{6} \mathrm{CH}_{2} \mathrm{COOH}$ & $376.97>292.99$ & 14 & 22 \\
\hline $8: 2$ FTUCA & $\begin{array}{l}\text { 8:2 fluorotelomer } \\
\text { unsaturated carboxylic } \\
\text { acid }\end{array}$ & $70887-84-2$ & $\mathrm{~F}\left(\mathrm{CF}_{2}\right)_{7} \mathrm{CF}=\mathrm{CHCOOH}$ & $456.97>393.02$ & 16 & 12 \\
\hline $8: 2$ FTCA & $\begin{array}{l}\text { 8:2 fluorotelomer } \\
\text { saturated carboxylic acid }\end{array}$ & $27854-31-5$ & $\mathrm{~F}\left(\mathrm{CF}_{2}\right)_{8} \mathrm{CH}_{2} \mathrm{COOH}$ & $476.97>393.05$ & 14 & 22 \\
\hline \multicolumn{7}{|c|}{ Mass-labeled analytes } \\
\hline M6:2 FTOH & {$\left[1,1-\mathrm{D}_{2}, 1,2-{ }^{13} \mathrm{C}_{2}\right]$ 6:2 FTOH } & N.A. ${ }^{a}$ & $\mathrm{~F}\left(\mathrm{CF}_{2}\right)_{6}{ }^{13} \mathrm{CH}_{2}{ }^{13} \mathrm{CD}_{2} \mathrm{OH}$ & $367.03>256.01$ & 12 & 18 \\
\hline M8:2 FTOH & {$\left[1,1-\mathrm{D}_{2}, 1,2-{ }^{13} \mathrm{C}_{2}\right] 8: 2 \mathrm{FTOH}$} & N.A. & $\mathrm{F}\left(\mathrm{CF}_{2}\right)_{8}{ }^{13} \mathrm{CH}_{2}{ }^{13} \mathrm{CD}_{2} \mathrm{OH}$ & $467.03>356.02$ & 12 & 22 \\
\hline MPFBA & ${ }^{13} \mathrm{C}_{4}$-PFBA & N.A. & $\mathrm{F}\left({ }^{13} \mathrm{CF}_{2}\right){ }_{3}{ }^{13} \mathrm{COOH}$ & $216.97>172.05$ & 14 & 8 \\
\hline MPFHxA & ${ }^{13} \mathrm{C}_{2}$-PFHxA & N.A. & $\mathrm{F}\left(\mathrm{CF}_{2}\right){ }_{4}{ }^{13} \mathrm{CF}_{2}{ }^{13} \mathrm{COOH}$ & $314.97>270.05$ & 14 & 8 \\
\hline MPFOA & ${ }^{13} \mathrm{C}_{4}-\mathrm{PFOA}$ & N.A. & $\mathrm{F}\left(\mathrm{CF}_{2}\right)_{4}\left({ }^{13} \mathrm{CF}_{2}\right)_{3}{ }^{13} \mathrm{COOH}$ & $416.97>372.06$ & 14 & 10 \\
\hline MPFNA & ${ }^{13} C_{5}$-PFNA & N.A. & $\mathrm{F}\left(\mathrm{CF}_{2}\right)_{4}\left({ }^{13} \mathrm{CF}_{2}\right)_{4}{ }^{13} \mathrm{COOH}$ & $467.97>423.00$ & 16 & 6 \\
\hline M6:2 FTUCA & ${ }^{13} C_{2}-6: 2$ FTUCA & N.A. & $\mathrm{F}\left(\mathrm{CF}_{2}\right)_{5} \mathrm{CF}={ }^{13} \mathrm{CH}^{13} \mathrm{COOH}$ & $358.97>294.04$ & 16 & 14 \\
\hline M6:2 FTCA & ${ }^{13} C_{2}-6: 2$ FTCA & N.A. & $\mathrm{F}\left(\mathrm{CF}_{2}\right)_{6}{ }^{13} \mathrm{CH}_{2}{ }^{13} \mathrm{COOH}$ & $379.03>294.02$ & 14 & 14 \\
\hline M8:2 FTUCA & ${ }^{13} C_{2}-8: 2$ FTUCA & N.A. & $\mathrm{F}\left(\mathrm{CF}_{2}\right)_{7} \mathrm{CF}={ }^{13} \mathrm{CH}^{13} \mathrm{COOH}$ & $458.97>394.05$ & 18 & 18 \\
\hline M8:2 FTCA & ${ }^{13} \mathrm{C}_{2}-8: 2$ FTCA & N.A. & $\mathrm{F}\left(\mathrm{CF}_{2}\right)_{8}{ }^{13} \mathrm{CH}_{2}{ }^{13} \mathrm{COOH}$ & $478.97>394.05$ & 14 & 22 \\
\hline
\end{tabular}

a N.A., not available.

supernatants of the extractions were combined and allowed to evaporate under a gentle stream of nitrogen to $500 \mu \mathrm{L}$. Then the concentrated extractions were mixed with $500 \mu \mathrm{L} \mathrm{MeOH}$ before cleanup.

For $\mathrm{MeOH}$ extraction, $6 \mathrm{~mL}$ of $\mathrm{MeOH}$ were added to the samples. After mixing and shaking for $8 \mathrm{~h}$, the $\mathrm{MeOH}$ were separated by centrifugation $(2686 \times g, 20 \mathrm{~min})$ and transferred to a second PP tube. The samples were then extracted twice with $2 \times 6 \mathrm{~mL}$ solvents. All organic supernatants were combined and allowed to evaporate to $1.0 \mathrm{~mL}$ under nitrogen before being cleaned by Envi-Carb graphitized carbon.

All extractions were performed in quadruplicate. The extracts were cleaned up by Envi-Carb graphitized carbon as reported by Ruan et al. [38] with some modifications. Briefly, a $500 \mu \mathrm{L}$ aliquot of the extract was placed into a $2 \mathrm{~mL}$ disposable PP microcentrifuge tube, which contained $20 \mathrm{mg}$ Envi-Carb graphitized carbon that was treated with $40 \mu \mathrm{L}$ of $0.1 \mathrm{M} \mathrm{NaOH}$. The tube was capped and vortexed for $1 \mathrm{~min}$, then centrifuged at $8600 \times \mathrm{g}$ for $30 \mathrm{~min}$. The supernatant was gathered before UPLC-MS/MS analysis.

\subsection{Selection of extractants for poly-and perfluorinated acids and SPE cleanup}

Studies have shown ACN [35], MeOH [26], MTBE [36], NaOH$\mathrm{MeOH}$ [37], $\mathrm{NaOH}-\mathrm{MTBE}$ [30] are efficient in the extraction of PFAAs from environmental samples. To evaluate the capacity of different solvents, recovery tests for FTOH degradation products of poly- and perfluorinated acids in soils and plant roots and shoots were conducted. Two grams of blank soils or $0.5 \mathrm{~g}$ blank plant tissues were weighed in $15 \mathrm{~mL}$ PP centrifuge tubes. Before extraction, $50 \mu \mathrm{L}$ of poly- and perfluorinated acids mixture solutions $(200 \mathrm{ng} / \mathrm{mL}$ for each analyte in $\mathrm{MeOH}$ ) were added and aged for $24 \mathrm{~h}$.

For the extraction by MTBE and NaOH-MTBE, all samples were extracted according to the methods of Hansen et al. [36] and Vestergren et al. [31], respectively, with some modifications. Briefly, $1.5 \mathrm{~mL}$ of water (or $0.4 \mathrm{M} \mathrm{NaOH}$ solution) was added to the tube. After mixing for $30 \mathrm{~min}, 2 \mathrm{~mL}$ of $0.25 \mathrm{M} \mathrm{Na}_{2} \mathrm{CO}_{3} / \mathrm{NaHCO}_{3}$ buffer and $1 \mathrm{~mL}$ of $0.5 \mathrm{M}$ TBAHS solution were added. After thorough mixing, $5 \mathrm{~mL}$ of MTBE was added to the solution. The mixture was shaken for $8 \mathrm{~h}$, and then centrifuged $(2686 \times \mathrm{g})$ for $20 \mathrm{~min}$. The organic and aqueous layers were separated by centrifugation, and MTBE was transferred to a second PP tube. The aqueous mixture was extracted twice with $2 \times 5 \mathrm{~mL}$ MTBE. All organic supernatants of the three extractions were combined, evaporated to dryness under a gentle stream of nitrogen, and then reconstituted in $1.0 \mathrm{~mL}$ of $\mathrm{MeOH}$ before SPE cleanup.

For the extraction by $\mathrm{ACN}, \mathrm{MeOH}$, or $0.05 \mathrm{M} \mathrm{NaOH}$ in $\mathrm{MeOH}$ $(\mathrm{NaOH} / \mathrm{MeOH}), 6 \mathrm{~mL}$ of solvents were added to the samples. After mixing and shaking for $8 \mathrm{~h}$, the solvents were separated by centrifugation $(2686 \times \mathrm{g}, 20 \mathrm{~min})$ and then transferred to a second $\mathrm{PP}$ tube. The samples were extracted twice with $2 \times 6 \mathrm{~mL}$ solvents. All organic supernatants of the three extractions were combined and allowed to evaporate under nitrogen to $1.0 \mathrm{~mL}$ prior to SPE cleanup.

All extractions were performed in quadruplicate. Clean-up of the extracts were by Oasis WAX cartridges as reported by Taniyasu et al. [39] with some modifications. All the extracts were diluted with $30 \mathrm{~mL}$ milli-Q water (the solution $\mathrm{pH}$ was adjusted to 6 with $\mathrm{HCl}$ solution for $\mathrm{NaOH}-\mathrm{MeOH}$ extraction). Before SPE cleanup, the samples were filtered using a $0.45 \mu$ m nylon filter (Nylon 66, Tianjin Navigator Lab Instrument Co., Ltd, Tianjin, China) and then passed 
through cartridges pre-conditioned with $4 \mathrm{~mL}$ of $0.1 \%$ ammonium hydroxide in $\mathrm{MeOH}$ and $4 \mathrm{~mL}$ of Milli-Q water sequentially. The cartridges were then washed with $25 \mathrm{mM}$ sodium acetate buffer solution ( $\mathrm{pH} 4$ ) and dried completely under vacuum. The target compounds were eluted by $4 \mathrm{~mL}$ of $0.1 \%$ ammonium hydroxide in $\mathrm{MeOH}$. The elution was concentrated to $1.0 \mathrm{~mL}$ under a nitrogen stream. The final extraction was centrifuged $(8600 \times g)$ to remove particles before injection to UPLC-MS/MS.

\subsection{Effects of NaOH concentrations on 6:2 FTCA and 8:2 FTCA conversions}

The effects of $\mathrm{NaOH}$ concentrations on the conversions of $6: 2$ FTCA and 8:2 FTCA were determined. Briefly, $50 \mathrm{~mL}$ of $50 \mathrm{ng} / \mathrm{mL} \mathrm{6:2}$ FTCA (or 8:2 FTCA) was prepared in $0.01 \mathrm{M} \mathrm{NaOH} / \mathrm{MeOH}$ and $0.05 \mathrm{M}$ $\mathrm{NaOH} / \mathrm{MeOH}$, with continuous shaking on a rotary shaker $\left(25^{\circ} \mathrm{C}\right)$ at $125 \mathrm{rpm}$. At increasing time intervals (1, 3, 5, 7, 12 and $24 \mathrm{~h}), 0.5 \mathrm{~mL}$ solution was removed and neutralized with $\mathrm{HCl}$ immediately. The concentrations of 6:2 FTCA and 6:2 FTUCA (or 8:2 FTCA and 8:2 FTUCA) in the solution were determined using UPLC-MS/MS. Fifty $\mathrm{ng} / \mathrm{mL}$ 6:2 FTCA (or 8:2 FTCA) in $\mathrm{MeOH}$ without $\mathrm{NaOH}$ was used as control. The experiments were repeated two times.

\subsection{Instrumental analysis and quantification}

The purified sample extracts were analyzed using a Waters ultra-performance liquid chromatography (UPLC) system coupled to a Xevo TQS tandem mass spectrometer (MS/MS) with an electrospray ionization (ESI) interface. The separation of the FTOHs was achieved on a BEH Shield RP18 column $(1.7 \mu \mathrm{m}$ particles, $150 \mathrm{~mm} \times 2.1 \mathrm{~mm}$, Waters) with a $1 \mathrm{mM}$ ethanolamine in water/MeOH gradient mobile phase at a flow rate of $0.15 \mathrm{~mL} / \mathrm{min}$. $\mathrm{MeOH}$ was initialized at $50 \%$, then ramped to $85 \%$ in $1.0 \mathrm{~min}$ and held for $5.0 \mathrm{~min}$, and ramped back to $50 \%$ in $0.5 \mathrm{~min}$ and held for $3.5 \mathrm{~min}$. Column temperature was maintained at $35^{\circ} \mathrm{C}$. The FTOHs degradation products of poly- and perfluorinated acids were separated through a BEH C18 column $(1.7 \mu \mathrm{m}$ particles, $50 \mathrm{~mm} \times 2.1 \mathrm{~mm}$, Waters) with column temperature setting at $35^{\circ} \mathrm{C}$. A binary gradient elution program was applied with a constant flow rate of $0.4 \mathrm{~mL} / \mathrm{min}$. The mobile phase consisted of solvent (A) ACN and (B) $0.15 \%$ acetic acid in water, with an initial gradient of $5 \%$ A. At 2.5 min, the gradient increased to $60 \% \mathrm{~A}$ and held until $4.0 \mathrm{~min}$, then linearly reverted to original conditions at $4.5 \mathrm{~min}$. The column was reconditioned for $1.5 \mathrm{~min}$ at the starting composition of $5 \%$ A prior to the next injection.

Five microliters of solution was injected. The ESI source was operated in the negative ion mode with a capillary voltage of $3.0 \mathrm{kV}$, source temperature of $120^{\circ} \mathrm{C}$ for FTOHs, and $150^{\circ} \mathrm{C}$ for poly- and perfluorinated acids. Nitrogen was used as desolvation gas (flow rate $600 \mathrm{~L} / \mathrm{h}$, temperature $350^{\circ} \mathrm{C}$ ) and as cone gas (flow rate $50 \mathrm{~L} / \mathrm{h}$ ). Argon was used as collision gas at a flow rate of $0.15 \mathrm{~mL} / \mathrm{min}$. The detection was performed by ESI-MS/MS analyses using the multiple reaction mode (MRM) by measuring the transition of the precursor ion $\rightarrow$ product ion for FTOHs and its metabolic products. Cone voltages and collision energies were optimized for each analyte to obtain the highest sensitivity and resolution. MS/MS parameters for the analytes including their quantitation transitions, cone voltages, and collision energies are listed in Table 1. The MassLynx Software v.4.1 (Waters) was used for instrument control, data acquisition and processing.

\subsection{Determination of FTOHs and their degradation products in biosolid-amended soils and plant tissues}

Before extraction, 10 isotope labeled internal standards were spiked ( $5 \mathrm{ng}$ of each standard) to $2 \mathrm{~g}$ of biosolids-amended soils or
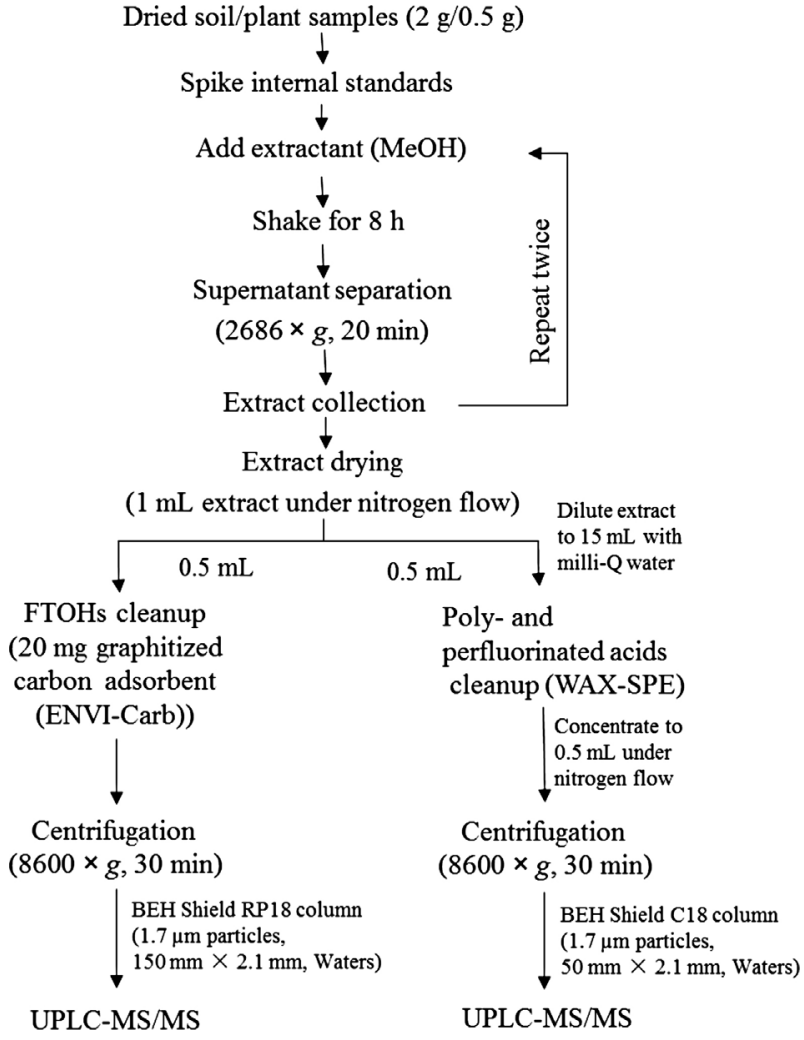

Fig. 1. Flow-chart of analytical method for FTOHs and poly- and perfluorinated acids in soil and plant samples.

$0.5 \mathrm{~g}$ of plants and aged for $24 \mathrm{~h} .6: 2 \mathrm{FTOH}, 8: 2 \mathrm{FTOH}$ and their degradation products of secondary polyfluorinated alcohols and polyand perfluorinated acids in soil and plant samples were extracted by $\mathrm{MeOH}$ simultaneously according to the methods described above. The $\mathrm{MeOH}$ extract was evaporated to $1.0 \mathrm{~mL}$. Half of the extract $(0.5 \mathrm{~mL})$ was subjected to Envi-Carb graphitized carbon cleanup for FTOHs analysis as described in Section 2.3. The other $0.5 \mathrm{~mL}$ extract was diluted with Milli-Q water to a final volume of $15 \mathrm{~mL}$ and subject to WAX-SPE cleanup for poly- and perfluorinated acids analysis as described in Section 2.4. The FTOHs and poly- and perfluorinated acids in purified sample extracts were analyzed by UPLC-MS/MS using BEH Shield RP18 and BEH C18 columns, respectively. The analytical procedure is shown by the flow chart in Fig. 1.

Matrix calibration curves using spiked uncontaminated samples that were extracted in analogy to the samples were applied for quantification. A seven point calibration curve ranging for all target analytes from 0.5 to $100 \mathrm{ng} / \mathrm{g}$ was performed at the beginning and at the end of every sample batch. Linear regression analysis was performed by plotting the peak area of the analyte over the analyte concentration, and the fitted lines had correlation coefficients $(R)$ values of at least 0.997 for all compounds. Recoveries were determined by comparing matrix-free direct injections of the same amount of spiked ${ }^{13} \mathrm{C}$ internal standards with ${ }^{13} \mathrm{C}$ spiked blank extracts and ${ }^{13} \mathrm{C}$ spiked samples. Compounds with no isotope labeled standard were corrected with the closest available internal standard, though this correction may lead to possible bias.

The limits of detection (LODs) and quantification (LOQs) for FTOHs and poly- and perfluorinated acids were defined as the concentration corresponding to the mean peak area plus three standard deviations $(x+3 \times \sigma)$ or plus 10 standard deviations $(x+10 \times \sigma)$ of extracts from the uncontaminated soils or plant tissues. The LODs and LOQs were measured for each matrix on replicate analyses $(n=7)$ of uncontaminated samples. 


\section{Results and discussion}

\subsection{Chromatograms of FTOHs and poly-and perfluorinated acids}

The separation of the FTOHs and their degradation products of poly- and perfluorinated acids were achieved on a ACQUITY UPLC BEH Shield RP18 column ( $1.7 \mu \mathrm{m}$ particles, $150 \mathrm{~mm} \times 2.1 \mathrm{~mm}$, Waters), and a ACQUITY UPLC BEH C18 column (1.7 $\mu \mathrm{m}$ particles, $50 \mathrm{~mm} \times 2.1 \mathrm{~mm}$, Waters), respectively. The later one is a trifunctionally bonded alkyl column, which can impact the retention, selectivity and sensitivity of ionizable compounds, thus has been used to separate PFAAs extensively [7,30,31,33]. The former one contains an embedded-polar group that combines the hydrophobicity of a straight-chain-alkyl ligand (C18) with the hydrophilicity of an embedded polar group (carbamate), which improves the retention of and peak shape of polyhydric substances [40,41]. Two ACQUITY UPLC BEH Shield RP18 columns with different lengths $(50 \mathrm{~mm} \times 2.1 \mathrm{~mm}$ and $150 \mathrm{~mm} \times 2.1 \mathrm{~mm})$ were compared and it was found that the longer column $(150 \mathrm{~mm} \times 2.1 \mathrm{~mm})$ had both higher separation efficiency and better peak shape.

The mass chromatograms of FTOHs and poly- and perfluorinated acids are shown in Fig. 2(a) and (b), respectively. Baseline separation was achieved within $6 \mathrm{~min}$ and $4.2 \mathrm{~min}$ for FTOHs and poly- and perfluorinated acids, respectively, except for 5:3 and 6:2 FTCA. GC/MS has been routinely used to analyze FTOHs in environmental samples $[27,42,43]$, with analytical time for $6: 2 \mathrm{FTOH}, 7: 2$ sFTOH and 8:2 FTOH ranged 8.5-12 min, about 1.4-2.0 times longer than our method. LC/MS/MS is widely utilized for the quantification of FTOHs degradation products [18,19,21-23]. The analytical time of eight degradation products (PFPeA, PFHxA, PFHpA, PFOA, PFNA, 7:3 FTCA, 8:2 FTUCA and 8:2 FTCA) reported was about 9.5 min [21], which were 2.3 times longer than our method. The fast analyses for both FTOHs and their degradation products obtained in this study suggested the effectiveness of UPLC-MS/MS separation.

\subsection{Selection of analysis method for FTOHs}

FTOHs in soil and plant tissues were extracted by EtOAc and $\mathrm{MeOH}$ and cleaned by Envi-Carb graphitized carbon. The results are shown in Table S2 in the Supplementary materials. EtOAc extraction was reported to have greater yields of FTOHs from plants than MTBE and dichloromethane did [7]. Results from this study showed that $\mathrm{MeOH}$ extractions gave satisfactory recoveries of $87-102 \%$, with relative standards deviations (RSDs) based on four replicate analyses at $4.5-7.4 \%$. These values were equivalent to those of EtOAc extraction, whose recoveries were in the range of $89-101 \%$, and RSDs were 3.2-9.5\%. However, EtOAc is not suitable to inject into UPLC-MS/MS directly, MeOH was thus used in the following study.

The extracted supernatants were cleaned up with graphitized carbon adsorbent to remove natural organic matters that are likely to cause matrix interference in the mass spectrometer. Addition of glacial acetic acid to graphitized carbon was used to saturate the ion exchange sites on the sorbents [44]. However, the acetic acid present could form adduct with FTOHs and suppress their ionization. Liu et al. [45] suggested that the water in $90 \% \mathrm{ACN} / 10 \%$ $\mathrm{NaOH}$ solvent extract was sufficient to saturate the ion exchange site during the analysis of soil samples. Ruan et al. [38] used EnviCarb graphitized carbon added with $1 \mathrm{M} \mathrm{NaOH}$ to clean up 6:2 fluorotelomer iodide and its degradation products in soil extracts. Therefore, graphitized carbon was treated with $\mathrm{NaOH}$ solution for FTOH cleanup in this experiment. We also tested the effectiveness of WAX-SPE for FTOHs cleanup following MeOH extraction, according to Taniyasu et al. [39]. We found that the recoveries of $6: 2 \mathrm{FTOH}$, 7:2 sFTOH and 8:2 FTOH in soil and plant matrices after $\mathrm{MeOH}$ (a)

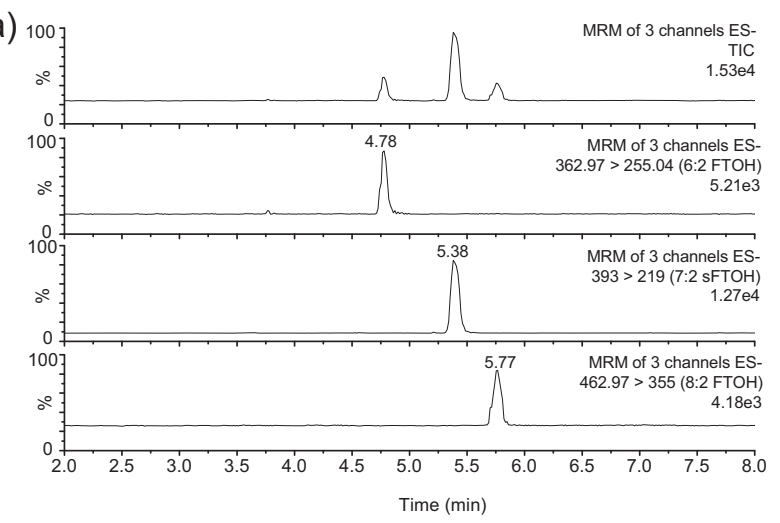

(b)
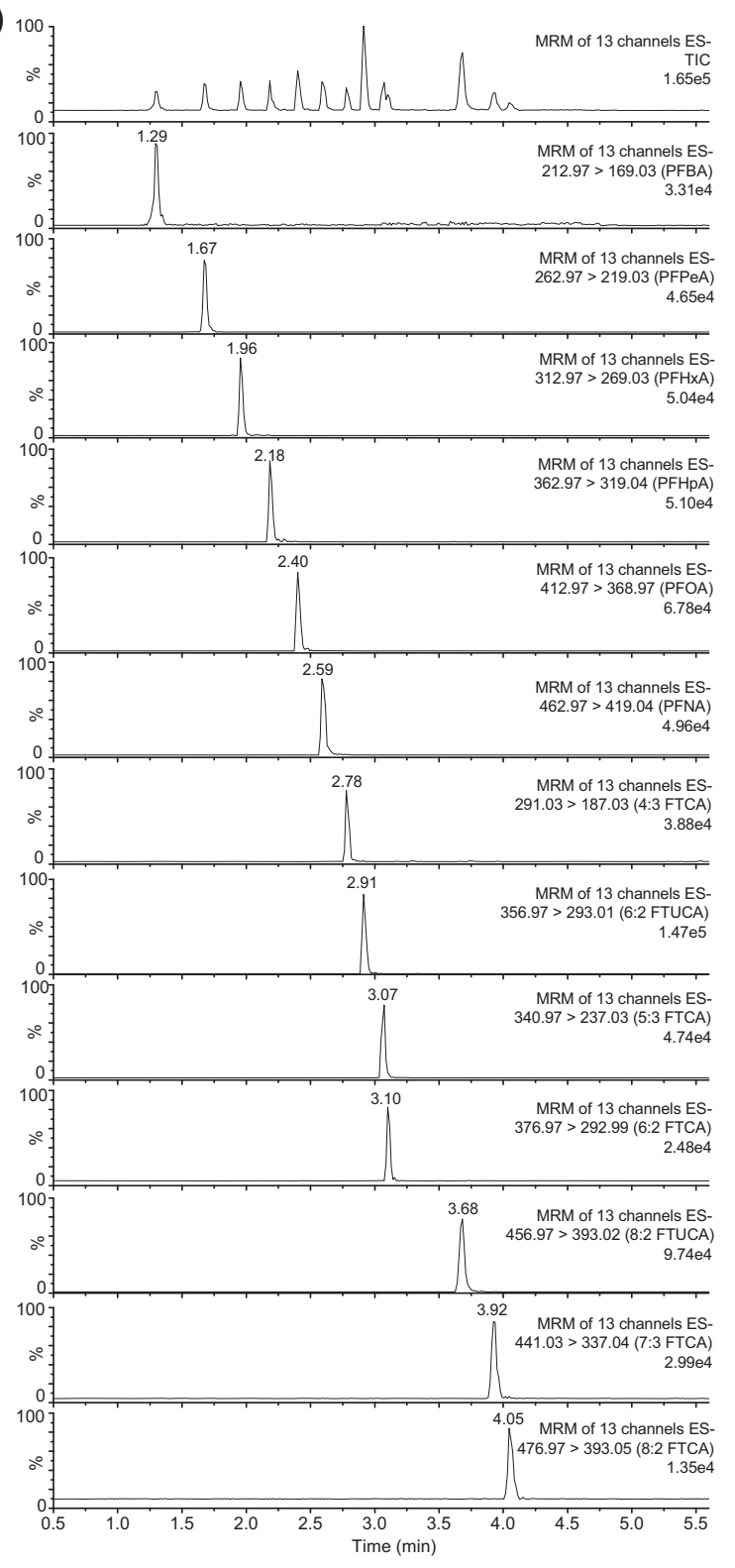

Fig. 2. Mass chromatograms of FTOHs (a) and poly- and perfluorinated acids (b) in standard mixture $(5 \mathrm{ng} / \mathrm{mL})$

extraction and WAX-SPE cleanup were less than 60\% (Table S3 in the Supplementary materials) which were much lower than EnviCarb graphitized carbon cleanup. Therefore, WAX-SPE was not used for FTOHs cleanup in the following experiment. 

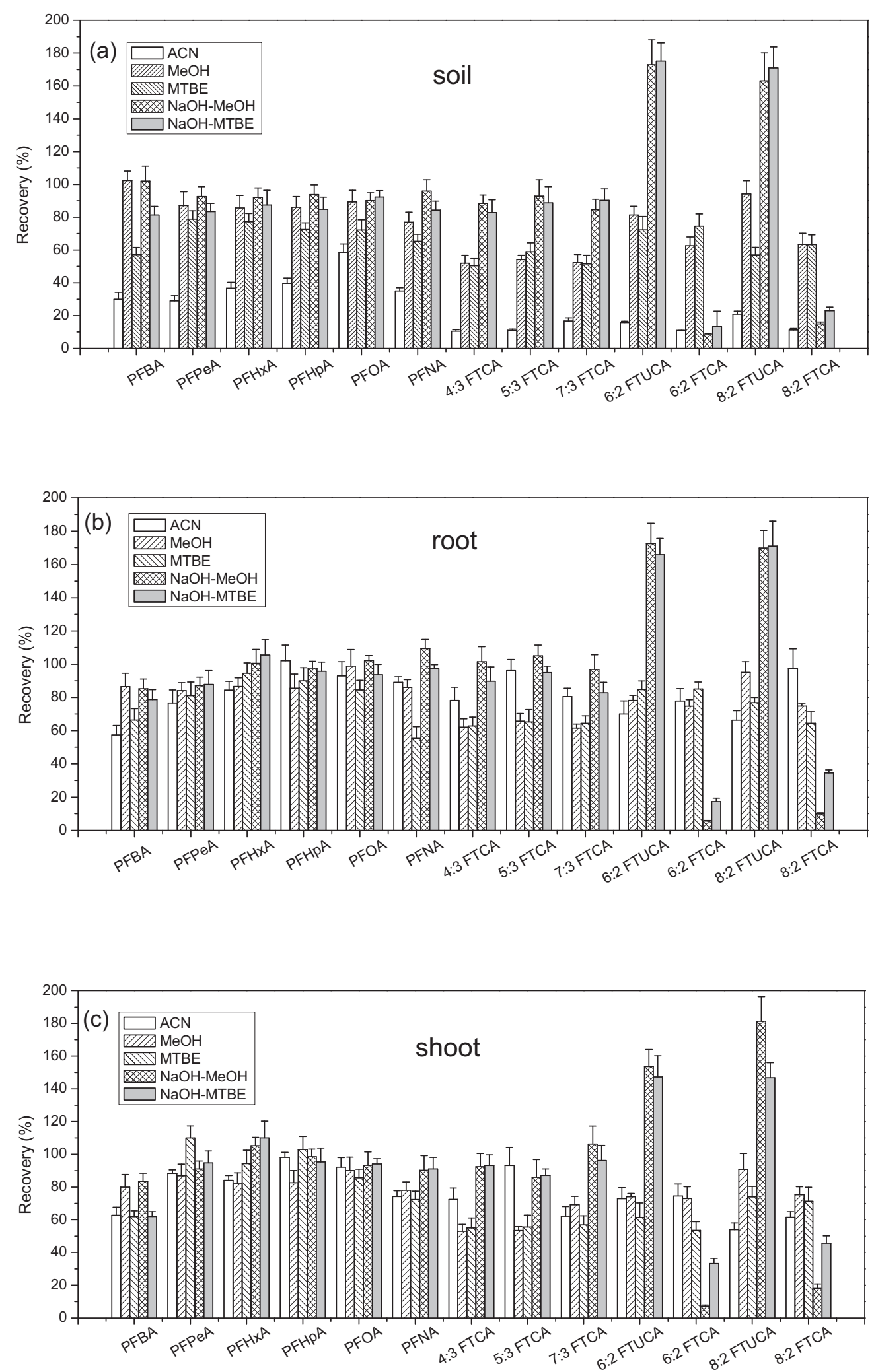

Fig. 3. Recoveries of spiked poly- and perfluorinated acids in soil (a), root (b) and shoot (c) by different solvents followed by WAX-SPE cleanup.

\subsection{Selection of extractants for poly- and perfluorinated acids analysis}

The methods available for biota analysis of PFAAs are mostly based on three extraction procedures: ion pair extraction, solvent liquid extraction, and alkaline digestion [34]. In this study, the extraction accuracy and precision of five solvents, $\mathrm{ACN}, \mathrm{MeOH}$, MTBE, NaOH-MeOH, and NaOH-MTBE coupled with WAX-SPE cleanup were compared. The results are shown in Fig. 3. The extraction recoveries for $\mathrm{ACN}$ were in the range of $11-59 \%$ for soils and 

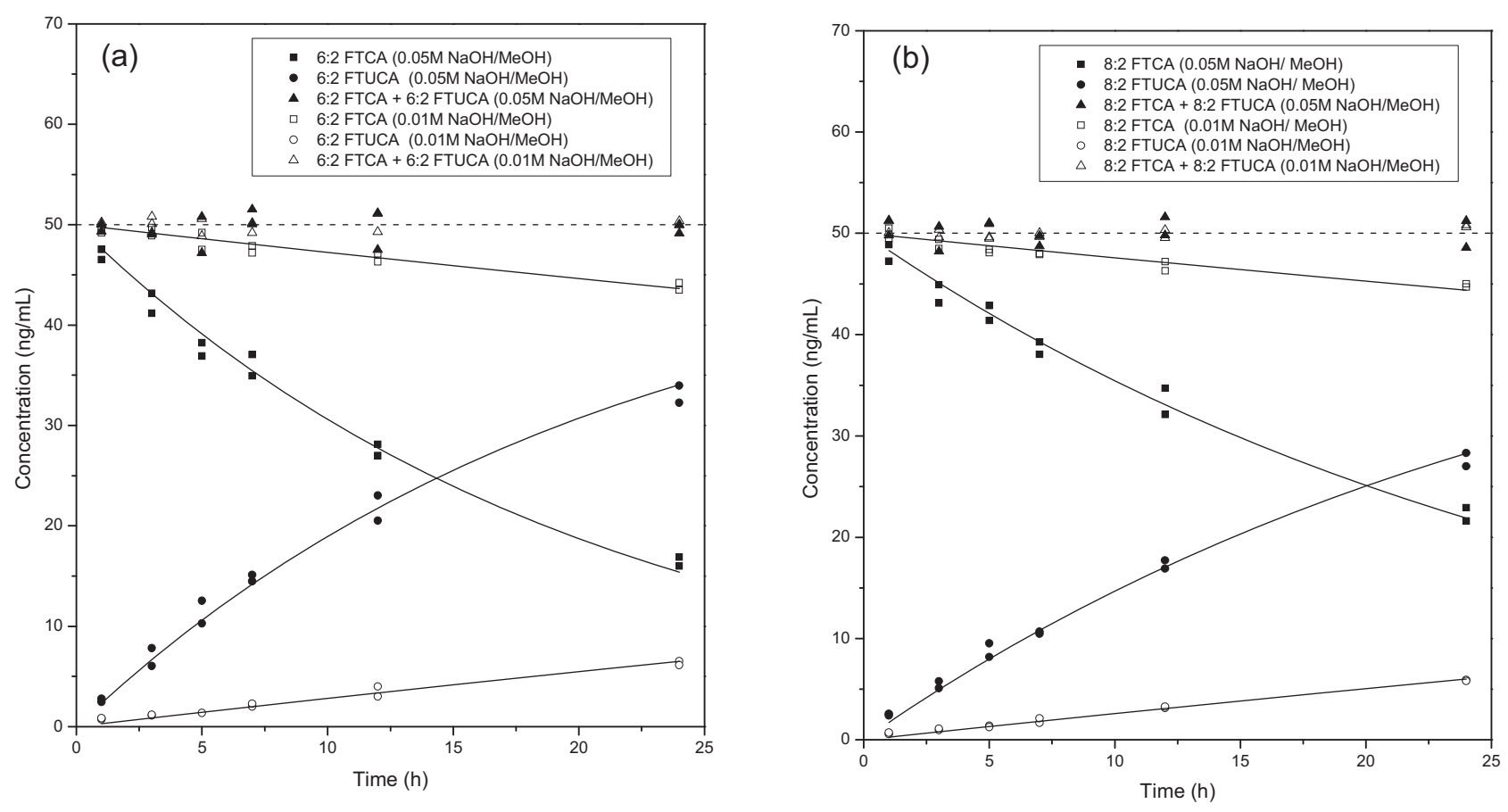

Fig. 4. Conversion kinetics of $50 \mathrm{ng} / \mathrm{mL} 6: 2 \mathrm{FTCA}$ and 8:2 FTCA in $0.01 \mathrm{M}$ and $0.05 \mathrm{M} \mathrm{NaOH} / \mathrm{MeOH}$.

54-102\% for plant tissues, which suggested that ACN is not suitable to extract poly- and perfluorinated acids from soils. $\mathrm{MeOH}$ and MTBE had similar extraction capacities, with the recoveries ranged $77-102 \%$ and $57-103 \%$, respectively, for PFCAs, 52-75 and $51-85 \%$, respectively for FTCAs, and $74-95$ and $57-85 \%$, respectively, for FTUCAs. The RSDs of $\mathrm{MeOH}$ method (1.9-10.8\%) was relatively smaller than those of MTBE method (4.1-14.5\%). The extraction capacities of $\mathrm{NaOH}-\mathrm{MeOH}$ and $\mathrm{NaOH}-\mathrm{MTBE}$ were equivalent to those of $\mathrm{MeOH}$ and MTBE for PFCAs, 18-39\% higher than those of $\mathrm{MeOH}$ and MTBE for 4:3 FTCA, 5:3 FTCA and 7:3 FTCA. However, the recoveries of $\mathrm{NaOH}-\mathrm{MeOH}$ and $\mathrm{NaOH}-\mathrm{MTBE}$ extraction for 6:2 FTCA and 8:2 FTCA were less than 46\%, while those for 6:2 FTUCA and 8:2 FTUCA were higher than 147\%, suggesting the underestimation of 6:2 FTCA and 8:2 FTCA, and overestimation of 6:2 FTUCA and 8:2 FTUCA when NaOH-MeOH and NaOH-MTBE were used as extractants. Liu et al. [19] reported that $\mathrm{NaOH}$ treatment may lead to the conversion of 6:2 FTCA to 6:2 FTUCA. Based on the above results, $\mathrm{MeOH}$ was used in the following experiment.

\subsection{Effect of $\mathrm{NaOH}$ concentration on the conversion of $6: 2$ FTCA and 8:2 FTCA}

In order to further evaluate the effect of $\mathrm{NaOH}$ treatment on the conversion of 6:2 FTCA and 8:2 FTCA, the conversion kinetics of FTCAs in $\mathrm{MeOH}$ solution with different $\mathrm{NaOH}$ concentrations were monitored over $24 \mathrm{~h}$. The results are shown in Fig. 4. No conversion was found for 6:2 FTCA and 8:2 FTCA in control. With the time increasing, the concentrations of 6:2 FTCA decreased, while those of 6:2 FTUCA increased gradually. At the end of the experiment, the concentrations of $6: 2$ FTCA in $0.01 \mathrm{M}$ and $0.05 \mathrm{M} \mathrm{NaOH} / \mathrm{MeOH}$ were $43.9 \pm 0.49 \mathrm{ng} / \mathrm{mL}$ and $16.4 \pm 0.63 \mathrm{ng} / \mathrm{mL}$, which are about $88 \%$ and $33 \%$ of their original levels, respectively, while the concentrations of $6: 2$ FTUCA in $0.01 \mathrm{M}$ and $0.05 \mathrm{M} \mathrm{NaOH} / \mathrm{MeOH}$ were $6.33 \pm 0.27 \mathrm{ng} / \mathrm{mL}$ and $33.1 \pm 1.21 \mathrm{ng} / \mathrm{mL}$, respectively (Fig. 4(a)). Similar decreases of 8:2 FTCA and increases of 8:2 FTUCA were also found (Fig. 4(b)). The experimental data were fitted with the first-order kinetics:

$$
\begin{aligned}
& Q_{1}=Q_{0} e^{-k_{1} t} \\
& Q_{2}=Q_{0}\left(1-e^{-k_{2} t}\right) \\
& t_{1 / 2}=\frac{\ln 2}{k}
\end{aligned}
$$

where $Q_{1}$ and $Q_{2}$ are concentrations of FTCAs and FTUCAs $(\mathrm{ng} / \mathrm{mL})$, respectively, at time $t(\mathrm{~h}) . k_{1}$ and $k_{2}$ are conversion rate constants $\left(\mathrm{h}^{-1}\right)$ for FTCAs and FTUCAs, respectively. $Q_{0}$ is the concentration of FTCAs at the beginning of the experiment, which is $50 \mathrm{ng} / \mathrm{mL} . t_{1 / 2}$ is the half-life of FTCAs conversion.

The conversion kinetics of FTCAs and FTUCAs satisfactorily fitted by the first-order kinetic model (Eqs. (1) and (2)), with $R^{2}$ values higher than 0.905 (Fig. 4, Table S4 in the Supplementary materials).

Table 2

Limits of detection (LODs, ng/g dw) and limits of quantification (LOQs, ng/g dw) for FTOHs and poly- and perfluorinated acids in soil and plant matrices.

\begin{tabular}{llllll}
\hline \multirow{2}{*}{ Analytes } & \multicolumn{2}{l}{ Soils } & & \multicolumn{2}{l}{ Plants } \\
\cline { 2 - 3 } \cline { 5 - 6 } & LOD & LOQ & & LOD & LOQ \\
\hline 6:2 FTOH & 0.12 & 0.38 & & 0.46 & 1.52 \\
7:2 sFTOH & 0.04 & 0.11 & 0.14 & 0.44 \\
8:2 FTOH & 0.11 & 0.37 & & 0.44 & 1.46 \\
PFBA & 0.06 & 0.20 & & 0.24 & 0.80 \\
PFPeA & 0.03 & 0.10 & 0.12 & 0.40 \\
PFHxA & 0.02 & 0.07 & 0.08 & 0.26 \\
PFHpA & 0.02 & 0.07 & 0.08 & 0.26 \\
PFOA & 0.03 & 0.10 & 0.12 & 0.40 \\
PFNA & 0.05 & 0.15 & 0.18 & 0.58 \\
4:3 FTCA & 0.02 & 0.07 & 0.08 & 0.26 \\
5:3 FTCA & 0.02 & 0.05 & 0.06 & 0.20 \\
7:3 FTCA & 0.02 & 0.07 & 0.08 & 0.26 \\
6:2 FTUCA & 0.01 & 0.03 & 0.04 & 0.13 \\
6:2 FTCA & 0.05 & 0.17 & 0.20 & 0.66 \\
8:2 FTUCA & 0.02 & 0.05 & 0.06 & 0.20 \\
8:2 FTCA & 0.06 & 0.18 & 0.22 & 0.70 \\
\hline
\end{tabular}


Table 3

Concentrations of FTOHs and poly- and perfluorinated acids (ng/g dw) in biosolids-amended soils and plants.

\begin{tabular}{|c|c|c|c|c|c|c|c|c|c|c|}
\hline \multirow[t]{2}{*}{ Analytes } & \multirow[t]{2}{*}{ Soil 1} & \multirow[t]{2}{*}{ Soil 2} & \multicolumn{3}{|l|}{ Plant 1} & \multicolumn{3}{|l|}{ Plant 2} & \multirow[t]{2}{*}{ Internal standards } & \multirow[t]{2}{*}{ Recoveries (\%) } \\
\hline & & & Root & Straw & Leaf & Root & Straw & Leaf & & \\
\hline $6: 2 \mathrm{FTOH}$ & $31.2(4.1)^{\mathrm{a}}$ & $57.4(5.9)$ & $1.74(0.03)$ & $<$ LOD & $1.84(0.22)$ & $1.97(0.07)$ & $<$ LOD & $6.36(0.59)$ & M6:2 FTOH & $88-97$ \\
\hline 7:2 sFTOH & $0.14(0.01)$ & $0.27(0.02)$ & $<$ LOD & $<$ LOD & $<$ LOD & $<$ LOD & $<$ LOD & $<$ LOD & N.A. ${ }^{b}$ & N.A. \\
\hline $8: 2 \mathrm{FTOH}$ & $12.8(1.7)$ & $25.1(1.2)$ & $<$ LOD & $<\mathrm{LOD}$ & $<$ LOD & $<$ LOD & $<$ LOD & $<$ LOD & M8:2 FTOH & $85-99$ \\
\hline PFBA & $0.64(0.05)$ & $0.38(0.02)$ & $4.02(0.39)$ & $9.72(1.1)$ & $5.16(0.02)$ & $2.84(0.25)$ & $7.92(1.02)$ & $10.2(0.10)$ & MPFBA & $78-92$ \\
\hline PFPeA & $0.14(0.01)$ & $0.15(0.01)$ & $5.20(0.51)$ & $25.5(2.1)$ & $13.2(1.0)$ & $5.43(0.44)$ & $18.2(1.1)$ & $8.88(0.78)$ & N.A. & N.A. \\
\hline PFHxA & $0.18(0.01)$ & $0.28(0.01)$ & $0.40(0.01)$ & $2.69(0.23)$ & $1.53(0.19)$ & $0.55(0.05)$ & $3.78(0.21)$ & $1.16(0.09)$ & MPFHxA & $75-88$ \\
\hline PFHpA & $0.48(0.02)$ & $1.05(0.12)$ & $0.29(0.02)$ & $0.26(0.03)$ & $0.71(0.20)$ & $0.22(0.01)$ & $0.33(0.06)$ & $0.52(0.26)$ & N.A. & N.A. \\
\hline PFOA & $166(13)$ & $347(11)$ & $4.43(0.39)$ & $0.53(0.03)$ & $3.18(0.12)$ & $4.94(0.08)$ & $1.08(0.13)$ & $5.85(0.44)$ & MPFOA & $82-99$ \\
\hline PFNA & $0.17(0.01)$ & $0.26(0.01)$ & $0.21(0.01)$ & $0.46(0.03)$ & $0.59(0.04)$ & $0.68(0.02)$ & $0.77(0.05)$ & $2.10(0.18)$ & MPFNA & $73-87$ \\
\hline $4: 3$ FTCA & $0.08(0.01)$ & $<$ LOD & $<\mathrm{LOD}$ & $<\mathrm{LOD}$ & $<$ LOD & $<$ LOD & $<\mathrm{LOD}$ & $<$ LOD & N.A. & N.A. \\
\hline 5:3 FTCA & $0.03(0.01)$ & $0.14(0.01)$ & $<$ LOD & $<$ LOD & $<$ LOD & $<$ LOD & $<$ LOD & $<$ LOD & N.A. & N.A. \\
\hline 7:3 FTCA & $0.10(0.01)$ & $0.13(0.01)$ & $<$ LOD & $<\mathrm{LOD}$ & $<$ LOD & $<$ LOD & $<\mathrm{LOD}$ & $<$ LOD & N.A. & N.A. \\
\hline 6:2 FTUCA & $0.07(0.01)$ & $0.10(0.01)$ & $0.31(0.03)$ & $0.38(0.02)$ & $0.14(0.01)$ & $0.26(0.07)$ & $0.12(0.01)$ & $0.15(0.01)$ & M6:2 FTUCA & $65-81$ \\
\hline $6: 2$ FTCA & $0.13(0.01)$ & $0.12(0.01)$ & $0.57(0.02)$ & $0.23(0.02)$ & $<\mathrm{LOD}$ & $0.44(0.04)$ & $0.29(0.02)$ & $<$ LOD & M6:2 FTCA & $60-77$ \\
\hline $8: 2$ FTUCA & $<$ LOD & $<$ LOD & $<\mathrm{LOD}$ & $<\mathrm{LOD}$ & $<$ LOD & $<$ LOD & $<$ LOD & $<$ LOD & M8:2 FTUCA & $80-95$ \\
\hline $8: 2$ FTCA & $<$ LOD & $<$ LOD & $<$ LOD & $<$ LOD & $<$ LOD & $<\mathrm{LOD}$ & $<$ LOD & $<$ LOD & M8:2 FTCA & $56-80$ \\
\hline
\end{tabular}

a Standard deviation for triplicate measurements.

b N.A., not available.

The $k_{1}$ values calculated from Eq. (1) were consistent with $k_{2}$ calculated from Eq. (2), indicating the conversion from FTCAs to FTUCAs. FTCAs in $0.05 \mathrm{M} \mathrm{NaOH} / \mathrm{MeOH}$ presented higher $k_{1}$ and lower $t_{1 / 2}$ values than those in $0.01 \mathrm{M} \mathrm{NaOH} / \mathrm{MeOH}$, suggesting that $\mathrm{NaOH}$ facilitate the conversion of FTCAs. 6:2 FTCA displayed faster conversion rate than that of $8: 2$ FTCA. The conversion of $6: 2$ and $8: 2$ FTCAs into the corresponding FTUCAs in the presence of $\mathrm{NaOH}$ may be the results of elimination reactions of halogenated fatty acids, such as the following reaction:

$\mathrm{F}\left(\mathrm{CF}_{2}\right)_{x} \mathrm{CH}_{2} \mathrm{COOH}+\mathrm{OH}^{-} \rightarrow \mathrm{F}\left(\mathrm{CF}_{2}\right)_{x-1} \mathrm{CF}=\mathrm{CHCOOH}+\mathrm{F}^{-}+\mathrm{H}_{2} \mathrm{O}(4)$

The effects of $\mathrm{NaOH}$ on FTCAs conversion suggest $\mathrm{NaOH}$ cannot be used in the extraction of FTCAs.

\subsection{Limit of detection and quantification}

The LODs and LOQs are presented in Table 2. The LOQs for soil were $0.11-0.38 \mathrm{ng} / \mathrm{g}$ dry weight (dw) for FTOHs and $0.03-0.20 \mathrm{ng} / \mathrm{g}$ $\mathrm{dw}$ for poly- and perfluorinated acids; while those for plant tissue were $0.44-1.52 \mathrm{ng} / \mathrm{g} \mathrm{dw}$ for FTOHs, and $0.13-0.80 \mathrm{ng} / \mathrm{g} \mathrm{dw}$ for poly- and perfluorinated acids, respectively. Yoo et al. [7,27] used EtOAc and MTBE to extract FTOHs from sludge-applied soils and plants, respectively, and directly analyzed by GC/MS without further cleaning. Their LOQs for FTOHs were $0.9-3.2 \mathrm{ng} / \mathrm{g}$ dw for soil, and $0.5-1.0 \mathrm{ng} / \mathrm{g} \mathrm{dw}$ for plant tissues. Our LOQs for FTOHs are equivalent to theirs.

\subsection{Analysis of environmental samples}

FTOHs and poly- and perfluorinated acids in soil and plant samples collected from biosolids-amended agricultural fields were extracted by $\mathrm{MeOH}$ and cleanup by activated graphitized carbon cleanup and WAX-SPE, respectively. The samples were analyzed in triplicate to establish the accuracy of the measurements. The extraction recoveries of isotope-labeled internal standards were 85-99\% for FTOHs, $73-99 \%$ for PFCAs, and $56-95 \%$ for FTCAs and FTUCAs (Table 3). No significant difference of recoveries between soils and plant tissues was found (data not shown).

6:2 FTOH and 8:2 FTOH were found in two biosolids-amended soils, with the total concentrations ranged from 12.8 to $57.4 \mathrm{ng} / \mathrm{g}$ dw. This level was comparable to that reported in biosolidsamended soils in Decatur, Alabama [27]. Only 6:2 FTOH was found in plant roots and leaves. 8:2 FTOH in plant tissues was under its limit of detection. This may suggest that 8:2 FTOH was less labile to transfer from soil to plant when compared with 6:2 FTOH. Chemical compounds reach aerial plant organs in two ways: from the air and with the transpiration stream. The findings that 6:2 FTOH accumulations in leaves, while did not in straws indicated the foliar uptake from the air.

PFBA, PFPeA, PFHxA, PFHpA, PFOA, PFNA were detected in soils and plant roots, straws and leaves. These PFCAs were considered the possible final degradation products of 6:2 FTOH and 8:2 FTOH [21]. Among these PFCAs, the one with the highest concentrations detected in soils were PFOA. However, it is worthy to note that the PFCAs in soils may be derived from the biodegradation of FTOHs and other related precursors currently in use [46], as well as direct introduction from biosolids [30]. The PFCAs in plants may be from direct plant uptake and precursor degradation within plants.

7:2 sFTOH, 7:3 FTCA, 8:2 FTCA and 8:2 FTUCA were reported to be the possible intermediate degradation products of $8: 2 \mathrm{FTOH}$ $[18,21]$. The existence of 7:2 sFTOH $(0.14$ and $0.27 \mathrm{ng} / \mathrm{g} \mathrm{dw})$ and 7:3 FTCA ( 0.10 and $0.13 \mathrm{ng} / \mathrm{g} \mathrm{dw}$ ) in soils gave direct evidences for the degradation of 8:2 FTOH in biosolids-amended soils under field condition. As the intermediate degradation products of $6: 2$ FTOH, 6:2 FTCA and 6:2 FTUCA were found in plant roots and straws. Moreover, the concentrations of 6:2 FTCA and 6:2 FTUCA in plants were higher than those in soils. This implied that not only soil microbes, but also plant may have the ability to degrade $6: 2$ FTOH.

\section{Conclusions}

In the present study, $\mathrm{MeOH}$ was selected to extract 6:2 FTOH, 8:2 FTOH, and their degradation products 7:2 sFTOH and 13 polyand perfluorinated acids from soils and plants simultaneously. $\mathrm{NaOH}$ in extractant facilitate the conversion of $6: 2$ and 8:2 FTCAs into the corresponding FTUCAs, thus should be avoided. FTOHs and poly- and perfluorinated acid extracts can be cleaned up by Envi-Carb graphitized carbon and WAX-SPE, respectively, prior to quantitative determination using UPLC-MS/MS. They were found in all the biosolids-amended agricultural soil and plant samples. This finding demonstrated contamination of FTOHs in soils and plants as a result of biosolids-amendment, and the degradation of FTOHs in soil-plant system. This paper firstly reported the quantitative determination of FTOHs and their degradation products in biosolids-amended soils and plants, and the methods developed here can be used to investigate the occurrence and fate of FTOHs in terrestrial environment. 


\section{Acknowledgments}

We thank Dr. Rixiang Huang of Georgia Institute of Technology and Dr. Low Sijia Pearlie of Nanyang Technological University for their English polishing, comments and suggestions on the manuscript. This study was supported by the National Natural Science Foundation of China (Projects 41371460 and 21321004) and the Chinese Academy of Sciences (XDB14020202, YSW2013B01).

\section{Appendix A. Supplementary data}

Supplementary data associated with this article can be found, in the online version, at http://dx.doi.org/10.1016/j.chroma.2015.05. 063

\section{References}

[1] J. Li, S. Del Vento, J. Schuster, G. Zhang, P. Chakraborty, Y. Kobara, K.C. Jones, Perfluorinated compounds in the Asian atmosphere, Environ. Sci. Technol. 45 (2011) 7241-7248

[2] X.P. Wang, C. Halsall, G. Codling, Z.Y. Xie, B.Q. Xu, Z. Zhao, Y.G. Xue, R. Ebinghaus, K.C. Jones, Accumulation of perfluoroalkyl compounds in Tibetan mountain snow: temporal patterns from 1980 to 2010, Environ. Sci. Technol. 48 (2014) $173-181$.

[3] L. Ahrens, Polyfluoroalkyl compounds in the aquatic environment: a review of their occurrence and fate, J. Environ. Monit. 13 (2011) 20-31.

[4] O. Sindiku, F. Orata, R. Weber, O. Osibanjo, Per- and polyfluoroalkyl substances in selected sewage sludge in Nigeria, Chemosphere 92 (2013) 329-335.

[5] M. Houde, A.O. De Silva, D.C.G. Muir, R.J. Letcher, Monitoring of perfluorinated compounds in aquatic biota: an updated review PFCs in aquatic biota, Environ. Sci. Technol. 45 (2011) 7962-7973.

[6] A. Karrman, I. Ericson, B. van Bavel, P.O. Darnerud, M. Aune, A. Glynn, S. Lignell, G. Lindstrom, Exposure of perfluorinated chemicals through lactation: levels of matched human milk and serum and a temporal trend, 1996-2004, in Sweden, Environ. Health Perspect. 115 (2007) 226-230.

[7] H.Yoo, J.W. Washington, T.M. Jenkins, J.J. Ellington, Quantitative determination of perfluorochemicals and fluorotelomer alcohols in plants from biosolidamended fields using LC/MS/MS and GC/MS, Environ. Sci. Technol. 45 (2011) 7985-7990.

[8] G.W. Olsen, J.M. Burris, D.J. Ehresman, J.W. Froehlich, A.M. Seacat, J.L. Butenhoff, L.R. Zobel, Half-life of serum elimination of perfluorooctanesulfonate, perfluorohexanesulfonate, and perfluorooctanoate in retired fluorochemical production workers, Environ. Health Perspect. 115 (2007) 1298-1305.

[9] J.M. Conder, R.A. Hoke, W. De Wolf, M.H. Russell, R.C. Buck, Are PFCAs bioaccumulative? A critical review and comparison with regulatory lipophilic compounds, Environ. Sci. Technol. 42 (2008) 995-1003.

[10] G.W. Olsen, J.L. Butenhoff, L.R. Zobel, Perfluoroalkyl chemicals and human fetal development: an epidemiologic review with clinical and toxicological perspectives, Reprod. Toxicol. 27 (2009) 212-230

[11] S.K. Ritter, Fluorochemicals go short, Chem. Eng. News 88 (2010) 12-17.

[12] A.B. Lindstrom, M.J. Strynar, E.L. Libelo, Polyfluorinated compounds: past, present, and future, Environ. Sci. Technol. 45 (2011) 7954-7961.

[13] A.M. Calafat, L.Y. Wong, Z. Kuklenyik, J.A. Reidy, L.L. Needham, Polyfluoroalkyl chemicals in the US population: data from the National Health and Nutrition Examination Survey (NHANES) 2003-2004 and comparisons with NHANES 1999-2000, Environ. Health Perspect. 115 (2007) 1596-1602.

[14] M.J.A. Dinglasan, Y. Ye, E.A. Edwards, S.A. Mabury, Fluorotelomer alcohol biodegradation yields poly- and perfluorinated acids, Environ. Sci. Technol. 38 (2004) 2857-2864

[15] D.A. Ellis, J.W. Martin, A.O. De Silva, S.A. Mabury, M.D. Hurley, M.P.S. Andersen, T.J. Wallington, Degradation of fluorotelomer alcohols: a likely atmospheric source of perfluorinated carboxylic acids, Environ. Sci. Technol. 38 (2004) 3316-3321.

[16] S.A. Styler, A.L. Myers, D.J. Donaldson, Heterogeneous photooxidation of fluorotelomer alcohols: a new source of aerosol-phase perfluorinated carboxylic acids, Environ. Sci. Technol. 47 (2013) 6358-6367.

[17] S.A. Gauthier, S.A. Mabury, Aqueous photolysis of 8:2 fluorotelomer alcohol, Environ. Toxicol. Chem. 24 (2005) 1837-1846.

[18] N. Wang, B. Szostek, R.C. Buck, P.W. Folsom, L.M. Sulecki, J.T. Gannon, 8-2 fluorotelomer alcohol aerobic soil biodegradation: pathways, metabolites, and metabolite yields, Chemosphere 75 (2009) 1089-1096.

[19] J.X. Liu, N. Wang, B. Szostek, R.C. Buck, P.K. Panciroli, P.W. Folsom, L.M. Sulecki, C.A. Bellin, 6-2 fluorotelomer alcohol aerobic biodegradation in soil and mixed bacterial culture, Chemosphere 78 (2010) 437-444.

[20] L. Zhao, P.W. Folsom, B.W. Wolstenholme, H. Sun, N. Wang, R.C. Buck, 6:2 fluorotelomer alcohol biotransformation in an aerobic river sediment system, Chemosphere 90 (2013) 203-209.

[21] S. Zhang, B. Szostek, P.K. McCausland, B.W. Wolstenholme, X.X. Lu, N. Wang, R.C. Buck, 6:2 and 8:2 fluorotelomer alcohol anaerobic biotransformation in digester sludge from a WWTP under methanogenic conditions, Environ. Sci. Technol. 47 (2013) 4227-4235.
[22] D.L. Nabb, B. Szostek, M.W. Himmelstein, M.P. Mawn, M.L. Gargas, L.M. Sweeney, J.C. Stadler, R.C. Buck, W.J. Fasano, In vitro metabolism of 8 2 fluorotelomer alcohol: interspecies comparisons and metabolic pathway refinement, Toxicol. Sci. 100 (2007) 333-344.

[23] S.H. Brandsma, M. Smithwick, K. Solomon, J. Small, J. de Boer, D.C.G. Muir Dietary exposure of rainbow trout to $8: 2$ and 10:2 fluorotelomer alcohols and perfluorooctanesulfonamide: uptake, transformation and elimination, Chemosphere 82 (2011) 253-258.

[24] B.G. Loganathan, K.S. Sajwan, E. Sinclair, K. Senthil Kumar, K. Kannan, Perfluoroalkyl sulfonates and perfluorocarboxylates in two wastewater treatment facilities in Kentucky and Georgia, Water Res. 41 (2007) 4611-4620.

[25] R. Guo, W.-J. Sim, E.-S. Lee, J.-H. Lee, J.-E. Oh, Evaluation of the fate of perfluoroalkyl compounds in wastewater treatment plants, Water Res. 44 (2010) 3476-3486.

[26] H. Sun, A.C. Gerecke, W. Giger, A.C. Alder, Long-chain perfluorinated chemicals in digested sewage sludges in Switzerland, Environ. Pollut. 159 (2011) 654-662.

[27] H. Yoo, J.W. Washington, J.J. Ellington, T.M. Jenkins, M.P. Neill, Concentrations, distribution, and persistence of fluorotelomer alcohols in sludge-applied soils near Decatur, Alabama, USA, Environ. Sci. Technol. 44 (2010) 8397-8402.

[28] J.J. Ellington, J.W. Washington, J.J. Evans, T.M. Jenkins, S.C. Hafner, M.P. Neill, Analysis of fluorotelomer alcohols in soils: optimization of extraction and chromatography, J. Chromatogr. A 1216 (2009) 5347-5354.

[29] J.W. Washington, H. Yoo, J.J. Ellington, T.M. Jenkins, E.L. Libelo, Concentrations, distribution, and persistence of perfluoroalkylates in sludge-applied soils near Decatur, Alabama, USA, Environ. Sci. Technol. 44 (2010) 8390-8396.

[30] B. Wen, L. Li, H. Zhang, Y. Ma, X.-Q. Shan, S. Zhang, Field study on the uptake and translocation of perfluoroalkyl acids (PFAAs) by wheat (Triticum aestivum L.) grown in biosolids-amended soils, Environ. Pollut. 184 (2014) 547-554.

[31] R. Vestergren, S. Ullah, I.T. Cousins, U. Berger, A matrix effect-free method for reliable quantification of perfluoroalkyl carboxylic acids and perfluoroalkane sulfonic acids at low parts per trillion levels in dietary samples, J. Chromatogr. A 1237 (2012) 64-71.

[32] H. Peng, K.J. Hu, F.R. Zhao, J.Y. Hu, Derivatization method for sensitive determination of fluorotelomer alcohols in sediment by liquid chromatography-electrospray tandem mass spectrometry, J. Chromatogr. A 1288 (2013) 48-53.

[33] J.G. Li, F.F. Guo, Y.X. Wang, J.Y. Liu, Z.W. Cai, J.L. Zhang, Y.F. Zhao, Y.N. Wu, Development of extraction methods for the analysis of perfluorinated compounds in human hair and nail by high performance liquid chromatography tandem mass spectrometry, J. Chromatogr. A 1219 (2012) 54-60.

[34] S. Valsecchi, M. Rusconi, S. Polesello, Determination of perfluorinated compounds in aquatic organisms: a review, Anal. Bioanal. Chem. 405 (2013) 143-157.

[35] C.R. Powley, S.W. George, M.H. Russell, R.A. Hoke, R.C. Buck, Polyfluorinated chemicals in a spatially and temporally integrated food web in the Western Arctic, Chemosphere 70 (2008) 664-672.

[36] K.J. Hansen, L.A. Clemen, M.E. Ellefson, H.O. Johnson, Compound-specific, quantitative characterization of organic: fluorochemicals in biological matrices, Environ. Sci. Technol. 35 (2001) 766-770.

[37] S. Zhao, L. Zhu, L. Liu, Z. Liu, Y. Zhang, Bioaccumulation of perfluoroalky carboxylates (PFCAs) and perfluoroalkane sulfonates (PFSAs) by earthworms (Eisenia fetida) in soil, Environ. Pollut. 179 (2013) 45-52.

[38] T. Ruan, B. Szostek, P.W. Folsom, B.W. Wolstenholme, R. Liu, J. Liu, G. Jiang, N. Wang, R.C. Buck, Aerobic soil biotransformation of 6:2 fluorotelomer iodide, Environ. Sci. Technol. (2013) 11504-11511.

[39] S. Taniyasu, K. Kannan, M.K. So, A. Gulkowska, E. Sinclair, T. Okazawa, N. Yamashita, Analysis of fluorotelomer alcohols, fluorotelomer acids, and shortand long-chain perfluorinated acids in water and biota, J. Chromatogr. A 1093 (2005) 89-97.

[40] T. Tylova, J. Olsovska, P. Novak, M. Flieger, High-throughput analysis of tetracycline antibiotics and their epimers in liquid hog manure using ultra performance liquid chromatography with UV detection, Chemosphere 78 (2010) 353-359.

[41] B. Avula, Y.H. Wang, Z. Ali, T.J. Smillie, I.A. Khan, Chemical fingerprint analysis and quantitative determination of steroidal compounds from Dioscorea villosa, Dioscorea species and dietary supplements using UHPLC-ELSD, Biomed. Chromatogr. 28 (2014) 281-294.

[42] A. Jahnke, L. Ahrens, R. Ebinghaus, C. Temme, Urban versus remote air concentrations of fluorotelomer alcohols and other polyfluorinated alkyl substances in Germany, Environ. Sci. Technol. 41 (2007) 745-752.

[43] J.W. Martin, D.C.G. Muir, C.A. Moody, D.A. Ellis, W.C. Kwan, K.R. Solomon, S.A Mabury, Collection of airborne fluorinated organics and analysis by gas chromatography/chemical ionization mass spectrometry, Anal. Chem. 74 (2002) 584-590.

[44] C.R. Powley, S.W. George, T.W. Ryan, R.C. Buck, Matrix effect-free analytica methods for determination of perfluorinated carboxylic acids in environmental matrixes, Anal. Chem. 77 (2005) 6353-6358.

[45] J. Liu, L.S. Lee, L.F. Nies, C.H. Nakatsu, R.F. Turco, Biotransformation of 8:2 fluorotelomer alcohol in soil and by soil bacteria isolates, Environ. Sci. Technol. 41 (2007) 8024-8030.

[46] K. Dasu, J.X. Liu, L.S. Lee, Aerobic soil biodegradation of 8:2 fluorotelomer stearate monoester, Environ. Sci. Technol. 46 (2012) 3831-3836. 